\title{
Design for a dark adaptometer
}

\author{
E. BRUCE GOLDSTEIN \\ University of Pittsburgh, Pittsburgh, Pennsylvania 15260
}

\begin{abstract}
A design for a simple dark adaptometer that makes use of a commercially available slide projector is described. The adaptometer can be used without a chart readout or can be modified to provide a chart readout of the dark-adaptation curve. The resulting dark adaptometer is suitable for use in student sensation and perception laboratories, clinical applications, and research applications that do not require Maxwellian view.
\end{abstract}

The measurement of the process of dark adaptation has long been an important concern of research in sensory psychology and physiology (Carr \& Ripps, 1967; Craik \& Vernon, 1941; Goldstein \& Berson, 1969; Hecht, Haig, \& Wald, 1935; Rushton, 1965; Wald, 1960), and has also been used in clinical diagnosis (Berson, Gouras, Gunkel, \& Myrianthopoulos, 1969; Goodman \& Gunkel, 1958) and as an exercise in the undergraduate sensation and perception laboratory (Riggs, Note 1). The present paper describes a design for a dark adaptometer which can be built easily and cheaply, used without a chart readout for the student laboratory, and modified to provide an automatic chart readout for research and clinical applications.

The unique feature of this dark adaptometer is that a commercially available slide projector is used both to project the stimuli and to vary their intensity. This results in important advantages: (1) the adaptometer is easily assembled, with few of the problems associated with setting up optical systems, and (2) it is less expensive by a factor of about 5 or 10 than the commonly used Goldmann-Weekers adaptometer (cf. Burian \& Hansen, 1960; Gunkel \& Bornschein, 1957; Lukowski, Sutherland, \& Goldthwaite, 1973).

A schematic diagram of the adaptometer is shown in Figure 1. The stimulus beam is projected from a Kodak Carousel projector, ${ }^{1} \mathrm{C}$, onto a rear-projection screen, $P$. Before reaching the screen, the bean passes through a rotating shutter, $S^{\prime}$ (d riven by motor, $M)$, filters at $F$, and an opening in the partition. $P^{\prime}$. The subject, who rests his chin on a chinrest at $S$, fixates at $F^{\prime}$ and controls the position of the projector slide tray by means of a remote control, $R$. The projector slide tray contains slides which are constructed as shown in Figure 2. A hole is punched

This research was supported by a grant from the Health Research and Services Foundation, Pittsburgh. Pennsylvania. I thank Laura Frishman, Elizabeth Goldstein, Toni Price, and Dan Schweitzer-Tong for their helpful suggestions, their comments on the manuscript, and for serving as subjects. I also thank Richard Petrak and Frank Valentich for help in designing and constructing the potentiometer apparatus shown in Figure 4.

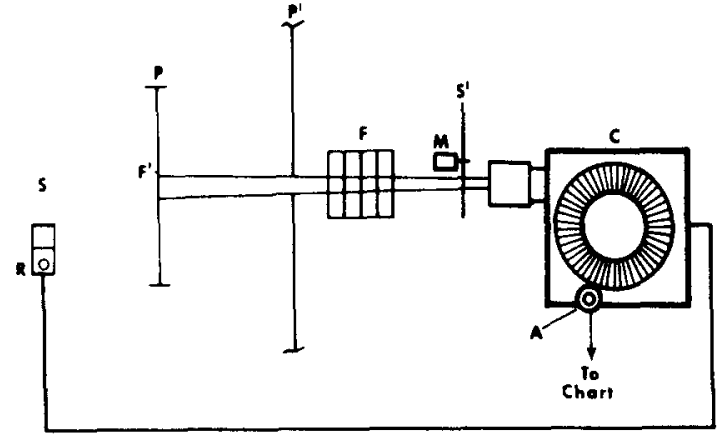

Figure 1. Schematic diagram of the adaptometer. See text for details.

in a piece of opaque paper ${ }^{2}$ and a small piece of Wratten neutral density filter is taped over the hole. The paper and filter are then mounted in a glass slide mount. ${ }^{3}$ The resulting projected image is a circular spot of light. The intensity of the spot is determined by the neutral density filter mounted over the hole. A series of these slides, ranging in density from 0.0 to $4.0 \log$ units in $0.1-\log$-unit steps, are placed in the projector slide tray so that reversing the slide tray decreases the intensity of the light.

The adaptometer operates similarly to the Békésy audiometer (Békésy, 1947). With the Békésy audiometer, the subject measures his own threshold by pressing a button when he detects the stimulus. and by releasing it when he cannot detect it. Pressing the button when the stimulus is above the subject's threshold activates a mechanism which drives the stimulus intensity down; releasing the button when the stimulus is below threshold reverses this mechanism and drives stimulus intensity up. This method of determining thresholds, sometimes called the "staircase method" or the "method of ups and downs" (Cornsweet. 1962), is used in the dark adaptoneter described in this paper. The stimulus intensity of the adaptometer is decreased by $0.1 \mathrm{log}$ unit when the subject briefly presses the reverse button of the projector remote control, and stimulus intensity is increased at a rate of $0.4 \mathrm{log}$ units per 


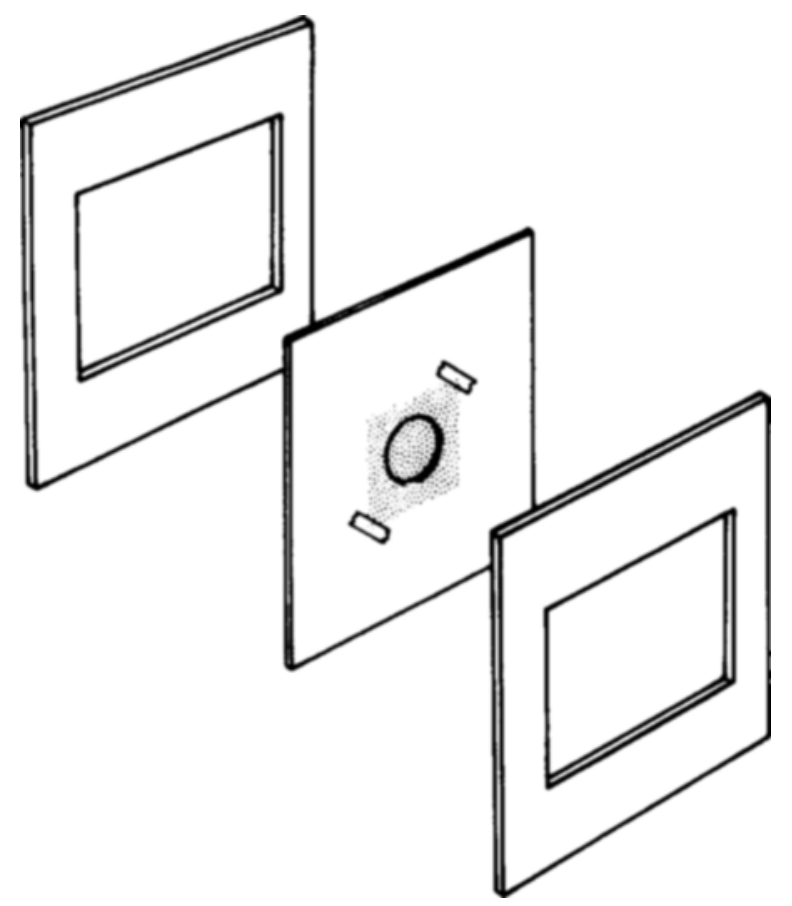

Figure 2. Exploded view of a neutral density slide. See text for details.

minute by the automatic advance control of the projector. 4

A dark-adaptation curve is measured as follows: The subject is seated at Position $S$ (Figure 1) and looks at the fixation light at $\mathrm{F}^{\prime}$. The subject is then light-adapted by flooding the screen with light from the projector. At the end of light adaptation, rotating Shutter $S^{\prime}$ is turned on and the slide tray is positioned so that a full-intensity spot (N.D. $=0.0$ ) is projected through the filter box at $F$. The filters at $F$ are then moved into the light beam to determine the wavelength of the test spot and to decrease the light intensity so that it is close to the subject's initial threshold. For example, for the curves in Figures 3 and 6 , a $520-\mathrm{nm}$ interference filter and $3.0 \mathrm{log}$ units of neutral density filter were moved into the beam at the beginning of dark adaptation.

When the subject sees the flashing light, he decreases the stimulus intensity by $0.1 \log$ unit by brietly pressing the reverse button on the remote control. The subject continues to press the button until he no longer sees the light. As the subject's sensitivity increases during dark adaptation, the spot again becomes visible and he again presses the reverse button until he can no longer see the light. After about 1 min of dark adaptation, the slide projector's automatic advance is turned on and the intensity automatically increases by $0.1 \log$ unit every $15 \mathrm{sec}$. If this increase in intensity brings the stimulus above the subject's threshold, he brings the intensity back down by pressing the reverse button. By keeping the intensity of the spot near his threshold in this way, the subject tracks his own dark-adaptation curve. The experimenter can determine the subject's sensitivity at any point in time by noting the position of the slide tray.

The dark-adaptation curve in Figure 3 was obtained by using the above procedure. The experimenter noted the tray position at $20 \mathrm{sec}, 30 \mathrm{sec}$. and $1 \mathrm{~min}$. and then every minute after the start of dark adaptation. Tray position is plotted on the ordinate and time on the abscissa. Since each position of the tray represents an increment of $0.1 \mathrm{log}$ unit of attenuation, this is equivalent to plotting log relative sensitivity vs. time.

The above procedure is ideally suited for use in undergraduate sensation and perception laboratories where the tray position can be continually monitored. For research and clinical applications, in which an automatic chart readout may be desirable, the device shown in Figure 4 can be added to the adaptometer. This device consists of a small wheel that is in contact with the slide tray and is connected to a potentiometer. As the slide tray turns, the wheel turns, thereby changing the effective resistance of the potentiometer. This potentiometer ${ }^{5}$ is part of the voltage divider circuit shown in Figure 5; it is connected to a battery and a chart recorder so that the input voltage to the chart recorder is proportional to the resistance of the potentiometer. The input voltage to the chart. $V_{c}$. equals $V_{b}\left(R_{1} / R_{2}\right)$, where $V_{b}$ is the voltage of the battery, $R_{1}$ is the effective resistance of the potentiometer, ${ }^{6}$ and $R_{2}$ is the total possible resistance of the potentiometer. Thus, as the slide tray turns, the wheel turns, changing $R_{1}$, the effective

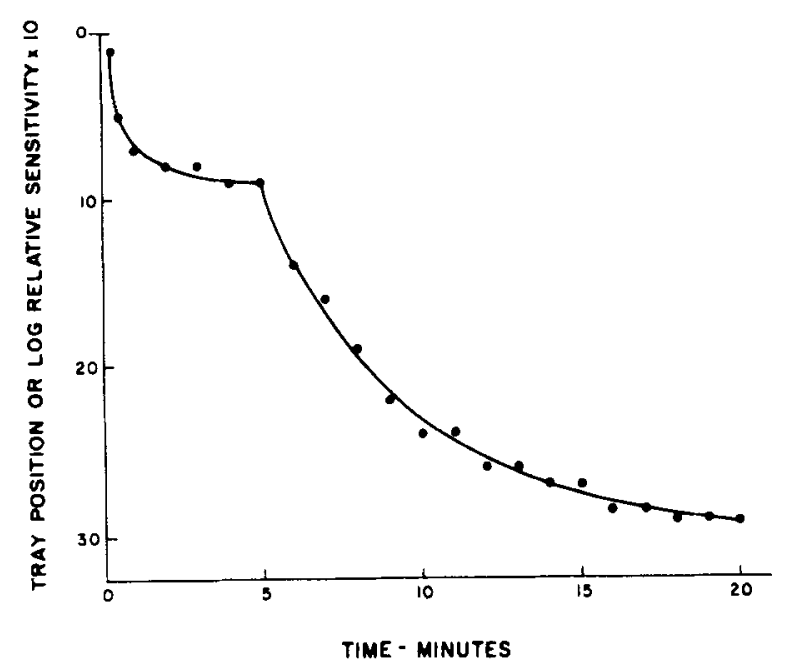

Figure 3. Dark adaptation curve measured by noting slide tray position during dark adaptation. Test flash: wavelength $=520 \mathrm{~nm}$; diameter $=7$ deg; duration $=2 / 3$ sec; frequency $=1 /$ sec. Center of test flash located 4 deg to the left of fixation. Light adaptation = $3.2 \log$ fL for $1 \mathrm{~min}$. 

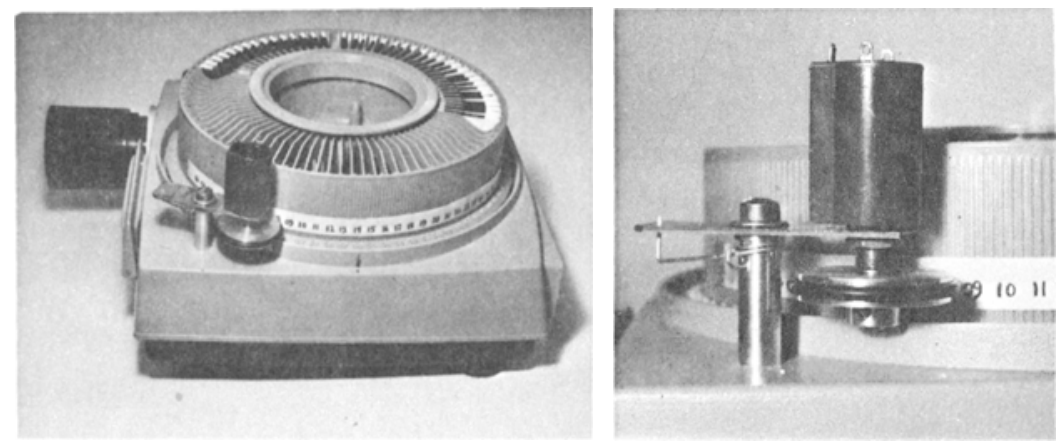

Figure 4. Carousel projector with device installed for chart readout. The potentiometer is shown without the wires which connect it to the battery and chart recorder. See text for details.

resistance of the potentiometer, and, therefore, $V_{c}$, the input voltage to the chart. The voltage recorded by the chart recorder therefore indicates the position of the slide tray. A chart readout of this type is shown in Figure 6 . The chart provides a continuous record of tray position; the downward excursions of the pen indicate when the subject pushes the reverse button to decrease the stimulus intensity, and the upward excursions indicate when the slide projector automatically advances the tray to increase the stimulus intensity.

\section{Additional Design Considerations}

A number of design considerations in addition to those discussed above should be noted before building the adaptometer.

Size of the stimulus spot. The diameter, D, of the stimulus spot depends on the diameter, $d$, of the hole in the slide (see Figure 2), the distance, $\mathrm{D}^{\prime}$, from the projector to the screen, and the focal length, F, of the projector lens. The approximate size of the stimulus spot can be determined by the formula $D=\mathrm{dD}^{\prime} / \mathrm{F}$.

Intensity of the stimulus spot. The intensity at each tray position should be calibrated in order to determine if the difference in log intensity between each tray position is equal (i.e., $0.1 \mathrm{log}$ unit in the present adaptometer). If the intensity difference is not equal, the dark-adaptation curve plotted by the chart recorder will be in error, since the ordinate of the chart will not be linearly related to log intensity. It is then necessary to correct the resulting darkadaptation curve. This problem is probably not important if the adaptometer is being used in the student laboratory. If, however, precise darkadaptation curves are required, it is necessary to carefully select and calibrate the filters so that the difference in intensity between each tray position is, in fact, equal.

Position of the stimulus spot. When making the stimulus slides, it is important to position the hole at exactly the same place on the slide mount, so that the spot will stay at the same place on the screen as intensity is varied.
Voltage input to the chart. It is desirable to design the adaptometer so that the voltage change that results from a change of one tray position $(0.1 \mathrm{log}$ unit) causes the chart pen to move an integral number of units on the chart paper (for example, in Figure 6, one tray position corresponds to about two chart divisions). The voltage change resulting from a change of one tray position can be determined by the formula $\Delta V_{\mathrm{c}}=\mathrm{KV}_{\mathrm{b}} / \mathrm{CT}$, where $\mathrm{K}$ is the distance that the slide tray moves when advanced on tray position $(\mathrm{K}=6.8 \mathrm{~mm}$ for a standard Carousel slide tray), $V_{b}$ is the voltage of the battery, $C$ is the circumference of the wheel that is in contact with the slide tray, and $T$ is the total number of turns of the potentiometer. Fine adjustments to the voltage input can be made by inserting a variable resistor between the positive pole of the battery and the potentiometer. Increasing the resistance of this resistor causes a decrease in the voltage change caused by a change of one tray position.

Adaptation intensities. An alternative to using the projector light source for light adaptation is to use an additional light positioned in front of the projection screen. This additional light might be needed for high adapting intensities. The adaptometer described in this paper may not, however, be satisfactory if very

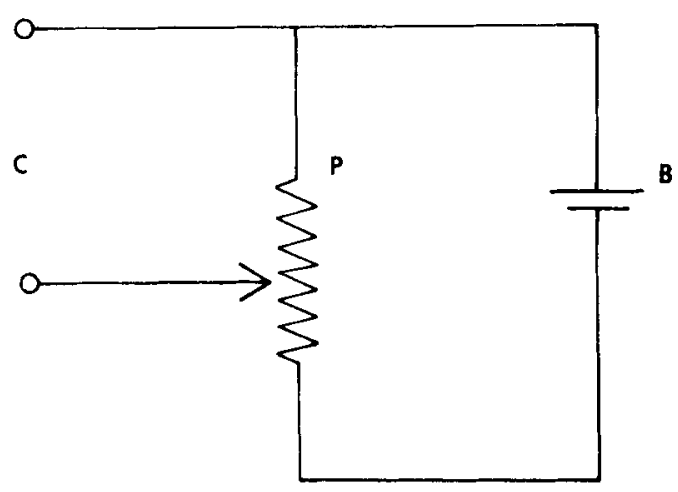

Figure 5. Voltage divider circuit for chart readout. Potentiometer, $P$, is connected to battery, B, and chart recorder, $C$. 


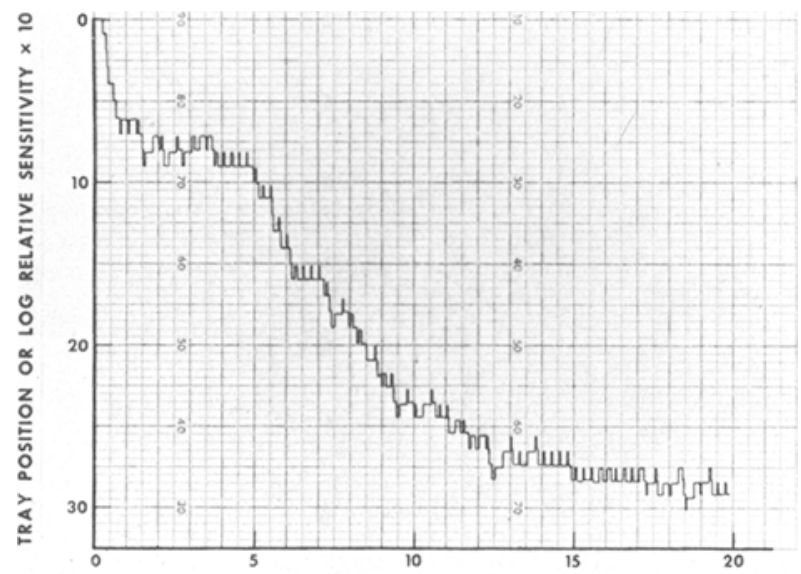

TIME - MINUTES

Figure 6. Dark adaptation curve plotted with chart recorder. This curve was determined simultaneously with the one in Figure 3. See text for details.

high adapting intensities are required. In that case, Maxwellian view optics may be necessary to achieve the required intensities.

Projector noise. One of the disadvantages of this system is that the Carousel projector makes a noise every time the tray position changes, and, therefore, provides a cue to the subject that intensity is changing. This problem can be overcome by using white noise to mask the projector noise, ${ }^{7}$ as was done during the measurement of the dark-adaptation curves in Figures 3 and 6.

Stray light. The Carousel projector causes a large amount of stray light. The best solution to this problem is to place the projector in one room and the subject in another (see the partition, $\mathrm{P}^{\prime}$, in Figure 1). Two added advantages of this solution are that projector noise is decreased and the experimenter does not have to dark-adapt with the subject.

\section{Summary}

A design for a simple dark adaptometer is described. The unique feature of the dark adaptometer is that it uses a commercially available slide projector both as a source of light and to control the intensity of the light. Addition of a series of neutral density slides and a shutter, filter holder, fixation light, screen and chinrest complete the adaptometer. Adding a simple potentiometer circuit to the Carousel projector makes it possible to obtain an automatic chart readout of the dark-adaptation curve.

\section{REFERENCE NOTE}

1. Riggs, L. A. Night vision and dark adaptation. Unpublished laboratory instructions, Department of Psychology, Brown University, 1963.

\section{REFERENCES}

BÉKÉSY, G. von. A new audiometer. Acta Otolaryngologica, 1947, 35, 411-422.

Berson, E. L., Gouras, P., Gunkel, R. D., \& MyrianThopoulos, N. C. Rod and cone responses in sex-linked retinitis pigmentosa. Archives of Ophthalmology, 1969, 81, 215-225.

Burian, H. M., \& Hansen, W. D. An automatic self-registering apparatus for the recording of global dark adaptation thresholds. Documenta Ophthalmologica, 1960, 26, 279-285.

CARR, R. E., \& RIPPs, H. Rhodopsin kinetics and rod adaptation in Oguchi's disease. Investigative Ophthalmology, 1967, 6, 426-436.

Cornsweet, T. N. The staircase method in psychophysics. American Journal of Psychology, 1962, 75, 485-491.

Craik, K. J. W., \& Vernon, M. D. The nature of dark adaptation. British Journal of Psychology, 1941, 32, 62-81.

Goldstein, E. B., \& Berson, E. L. Cone dominance of the human early receptor potential. Nature, 1969, 222, 1272-1273.

Goodman, G., \& Gunkel, R. D. Familial electroretinographic and adaptometric studies in retinitis pigmentosa. American Journal of Ophthalmology, 1958, 46, 142-172.

GunkeL. R. D., \& Bornschein, H. Automatic intensity control in testing dark adaptation. Archives of Ophthalmology, 1957, 57, 681-686.

Hecht, S., HaIG, C., \& WALD, G. The dark adaptation of retinal fields of different size and location. Journal of General Physiology, 1935, 19, 321-327.

Lukowsk1, R., Sutherland, J., \& Goldthwaite, D. Modifcation of the Goldmann-Weekers, adaptometer to a self-testing device. Canadian Joumal of Ophthalmology, 1973, 8, 478-487.

Rushton, W. A. H. Visual adaptation. Proceedings of the Royal Society, B, 1965, 162, 20-46.

WALD, G. Analysis of retinal function by a two-filter method. Journal of the Optical Society of America, 1960, 50, 633-641.

\section{NOTES}

1. A Model AF-2 Ektagraphic projector was used in the present adaptometer, but any Carousel projector with remote control and automatic timer is suitable.

2. Black Color-Aid paper was used for this adaptometer.

3. GEPE or Kinderman slide mounts are among those that are satisfactory.

4. Gunkel and Bornschein (1957) used a rate of change of $1.5 \mathrm{log}$ units per minute in their moditication of the Goldmann-Weekers adaptometer. In the present adaptometer, the rate at which the intensity decreases is controlled by the rate at which the subject presses the reverse button of the remote control. The rate at which the intensity increases is set at $0.4 \log$ unit per minute by setting the automatic timer to advance the slide tray every $15 \mathrm{sec}$. While $0.4 \mathrm{log}$ units per minute was found to be satisfactory for the present adaptonteter, it is also possible to obtain rates of 0.75 and $1.2 \mathrm{log}$ units per minute by setting the automatic timer at 8 or $5 \mathrm{sec}$, respectively.

5. For the present adaptometer, a 10-turn Clarostat Series 62 precision potentiometer with a total resistance of $50,000 \mathrm{ohms}$ and a linearity of $\pm 0.25 \%$ was used. The minimum number of potentiometer turns needed is determined by the circumference of the wheel attached to the potentiometer. In the present adaptometer, a wheel with a circumference of $13.2 \mathrm{~cm}$ caused the potentiometer to turn through about 2.6 revolutions $(13,000 \mathrm{ohms})$ for a $4.0 \mathrm{log}$ unit change in neutral density.

6. The effective resistance is the resistance between the slide arm and the upper fixed arm of the potentiometer (see Figure 5).

7. A convenient and effective masking source is the interstation hiss of an FM radio.

(Received for publication January 9, 1975; revision received February 28, 1975.) 